\title{
Risk of Spina Bifida and Maternal Cigarette, Alcohol, and Coffee Use during the First Month of Pregnancy
}

\author{
Corey M. Benedum, Mahsa M. Yazdy, Allen A. Mitchell and Martha M. Werler * \\ Slone Epidemiology Center at Boston University, 1010 Commonwealth Ave. Boston, MA 02215, USA; \\ E-Mails: cbenedum@bu.edu (C.M.B.); mahsa@bu.edu (M.M.Y.); allenmit@bu.edu (A.A.M.) \\ * Author to whom correspondence should be addressed; werler@bu.edu; Tel.: +1-612-734-6006; \\ Fax: +1-617-738-5119.
}

Received: 19 June 2013; in revised form: 23 July 2013 / Accepted: 24 July 2013 /

Published: 2 August 2013

\begin{abstract}
This study was conducted to assess the association between the risks of spina bifida (SB) in relation to cigarette, alcohol, and caffeine consumption by women during the first month of pregnancy. Between 1988-2012, this multi-center case-control study interviewed mothers of $776 \mathrm{SB}$ cases and 8,756 controls about pregnancy events and exposures. We evaluated cigarette smoking, frequency of alcohol drinking, and caffeine intake during the first lunar month of pregnancy in relation to SB risk. Logistic regression models were used to calculate adjusted odds ratios and $95 \%$ confidence intervals. Levels of cigarette smoking (1-9 and $\geq 10 /$ day), alcohol intake (average $\geq 4$ drinks/day) and caffeine intake ( $<1,1$, and $\geq 2$ cups/day) were not likely to be associated with increased risk of SB. Further, results were similar among women who ingested less than the recommended amount of folic acid (400 $\mu \mathrm{g} / \mathrm{day})$.
\end{abstract}

Keywords: spina bifida; alcohol consumption; caffeine consumption; cigarettes; folic acid; birth defects

\section{Introduction}

Spina bifida (SB), a neural tube defect (NTD), is a serious birth defect affecting approximately 35 per 100,000 live births [1]. SB, like other NTDs, occurs when the neural tube fails to properly close 
within the first 28 days after conception [2]. Maternal folic acid (FA) ingestion during the periconceptional period has been found to decrease the risk of giving birth to an infant with a NTD [3-6]. Based upon these findings, mandatory FA fortification of enriched cereal grains began in 1998 in the U.S. and Canada [7]. After U.S. fortification, an increase in the blood folate levels of adults was observed [8,9], but not all women of childbearing age ingest the recommended amount of $400 \mu \mathrm{g}$ per day [7].

Because SB continues to occur among mothers who have ingested at least $400 \mu \mathrm{g}$ per day of FA, other factors have been considered to explain the etiology of this birth defect. Among these, and based on their established or hypothesized teratogenic properties in humans, are cigarette smoking, alcohol drinking, and caffeine consumption [10-14]. Despite the positive association between maternal smoking and some birth defects, as well as the presence of known teratogenic chemicals in cigarettes [11], the association between maternal smoking and NTDs has been inconclusive, with study findings ranging from a protective effect to an increase in risk $[10,11,14,15]$. Extreme alcohol intake is a known human teratogen, causing Fetal Alcohol Syndrome in some exposed fetuses. NTDs are not a typical component of Fetal Alcohol Syndrome, but case reports suggest a possible link [16]. Epidemiological studies of moderate or low alcohol intakes and NTDs are inconclusive [11,14,17]. Caffeine intake in late gestation affects fetal cardiovascular function, but its effects in early gestation on organogenesis in general and neural tube development in particular are not known [18]. One epidemiologic study showed a slight increase in SB risk for all sources of caffeine [12], whereas three others showed no association $[13,17,18]$.

FA metabolism is believed to be altered by exposure to cigarette smoke, alcohol, and caffeine. Smokers have lower plasma folate levels after adjustment for folate intake [19,20]. Alcohol interferes with folate transport and metabolism [21,22]. Lower plasma folate concentrations were observed in coffee drinkers in a cross-sectional study, but dietary folate or supplemental folic acid were not taken into account [23].

Utilizing data collected in the Boston University Slone Epidemiology Center Birth Defects Study, we tested the hypotheses that the risk of SB is associated with smoking, alcohol drinking, and coffee consumption during the first 28 days after the last menstrual period (LMP). Additionally, we investigated whether the risk would be greater in women who failed to ingest the recommended amount of folic acid.

\section{Methods}

\subsection{Study Population}

The Slone Epidemiology Center Birth Defects Study is an on-going case-control study in North America, which began in 1976 and has been described in detail elsewhere [24-27]. Cases of birth defects were identified through birth hospitals, tertiary care centers, and birth defect registries in Massachusetts (1976+); Philadelphia, PA (1976+); Toronto, ON, Canada (1976-2005); San Diego County, CA (2001+); and parts of New York State (2004+). Beginning in 1990, therapeutic abortions after 12 weeks' gestation and fetal deaths occurring after 20 weeks' gestation were eligible for the study if identified; however, these pregnancies were not routinely ascertained. Beginning in 1993, 
the study began ascertaining non-malformed controls from the same birth population that gave rise to cases. For the years prior to 1993, infants born with major malformations other than the one under study or those born with only minor malformations (e.g., hip clicks, toe anomalies) or nonstructural defects (e.g., cystic fibrosis) were used as controls.

The present study was restricted to subjects interviewed between 1988 and 2012 when questions on changes in behaviors were asked. Cases of SB were excluded if they had a conjoined twin, chromosomal anomaly, Mendelian-inherited disorder, a known syndrome, amniotic bands, or a body wall defect. Cases were then reviewed by a clinical geneticist to ensure that they met the case definition. For 1988-1992, controls were infants with minor malformations or non-structural defects; for 1993-2012, control subjects were non-malformed infants.

Maternal interviews were conducted within six months of delivery by trained study nurses; interviews were conducted in person until 1998 and, thereafter by telephone. The interview consisted of questions pertaining to socio-demographic factors, reproductive history, illness during pregnancy, details on prescription and over-the-counter medication use (including vitamins), and behavioral risk factors (e.g., cigarette smoking, alcohol drinking, and coffee consumption). Cases and controls whose maternal exposure information was missing were excluded from the specific analysis. To assess dietary intake, the long version Willett Food Frequency Questionnaire (FFQ) was administered from 1988-1997; it was replaced with a modified, shortened, version in 1998.

\subsection{Smoking}

For the period beginning two months before and throughout pregnancy, mothers were asked the average number of cigarettes smoked per day before and after any changes in amount and the dates of those changes. Using the maternal-reported average and accounting for changes, we calculated an estimated average number of cigarettes smoked by determining the total number of cigarettes smoked during the 28 days after the LMP and then averaging the total number over the 28 days. Mothers were categorized according to the calculated average amount of cigarettes smoked per day $(<1,1-9$, and $\geq 10)$ during the first lunar month after the LMP.

\subsection{Alcohol}

Mothers were asked about the average number of drinking days per week (frequency) and the average number of drinks per drinking day (intensity) of alcohol consumption two months prior to and during pregnancy, including changes in patterns of intake and the date of any such change. Maternal-reported averages and the change dates were used to estimate the total number of drinks per day and drinking days for the 28 days. A calculated average of the 28-day period was then determined. Mothers were categorized as a heavy drinker if they reported $\geq 4$ drinks per day at any time during the first lunar month of pregnancy. Mothers were also classified, using the calculated average, according to their frequency of consumption in days per week $(<1,1,2$, and $\geq 3)$ and the intensity of consumption as the number of drinks per drinking day $(<1,1,2$, and $\geq 3)$ during the first lunar month after the LMP. 


\subsection{Coffee}

From 1998 through 2012, mothers were asked about the average number of cups of caffeinated coffee, tea, and soda consumed two months before and during their pregnancy; changes in frequency and the timing of any changes were also recorded. Before 1998, data on changes in frequency use were not collected. Changes in the interview occurring in 2005 led to different categorizations for tea and soda that were incompatible with previous years and therefore the main analysis was restricted to coffee intake from 1998 through 2012. To assess the influence of other sources of caffeine, a sensitivity analysis was performed using coffee, soda, and tea data from 1998 through 2005. For both analyses, mothers were categorized by the average number of caffeinated beverages/coffee consumed per day (none, $<1,1$, and $\geq 2$ ) during the first lunar month of pregnancy based on the total number over the 28 day period divided by 28 days, taking any changes into account.

\subsection{Smoking, Alcohol, and Coffee Interaction}

We then assessed potential interactions among the exposure variables. The interactions were examined by pairs (smoking/heavy drinking, smoking/coffee, heavy drinking/coffee) and all together (smoking/heavy drinking/coffee). Women who were in the highest exposure category for each variable were then compared to women who were in the reference category.

\subsection{Folic Acid Intake}

FA intake during the first lunar month of pregnancy was calculated by summing the average daily folic acid intake from supplements and fortified foods. Natural folate was also included, but discounted by $30 \%$ due to its lower bioavailability compared to synthetic folic acid [28]. The residual energy adjustment method [29] was used to adjust all dietary variables for total caloric intake. Participants were then categorized according to total folic acid intake ( $<400$ and $\geq 400 \mu \mathrm{g} / \mathrm{day}$ ). Participants with extreme caloric intakes ( $<500$ or $>4,000 \mathrm{kcal} /$ day) or incomplete FFQ ( $\geq 3$ missing items) were excluded from analyses involving folic acid intake, with two exceptions: Women who reported $\geq 400 \mu \mathrm{g}$ per day of folic acid from vitamin supplements or who reported not taking any supplements containing folic acid were retained in the analysis. The former group was retained because those taking folic acid-containing vitamins would fall into the $\geq 400 \mu \mathrm{g}$ per day stratum regardless of dietary intake. The latter group was retained based upon previous studies in which non-users would not likely reach the $\geq 400 \mu \mathrm{g}$ per day stratum from diet alone [7]; therefore they were placed in the $<400 \mu \mathrm{g}$ per day category.

\subsection{Statistical Analysis}

Multiple logistic regression models were used to calculate crude (cORs) and adjusted odds ratios (aORs) and 95\% confidence intervals (CIs) for each level of cigarette, alcohol and coffee exposure, with the non-use of each as the reference category. Sociodemographic factors that were considered as potential confounders included: maternal race/ethnicity (non-Hispanic White, non-Hispanic Black, Hispanic, other), maternal age ( $<20,20-24,25-29,30-34, \geq 35$ years), maternal education $(<12,12$, $>12$ years), study center (Boston, MA, USA; Philadelphia, PA, USA; Toronto, ON, Canada; San 
Diego county, CA, USA; New York State, USA), body mass index (underweight, normal, overweight, obese; available for 1993 onward), non-steroidal anti-inflammatory (NSAID) drug use (yes, no), use of medication that is to known be a folic acid antagonist (yes, no), and amount of FA intake ( $<400$ $\mu \mathrm{g} /$ day, $\geq 400 \mu \mathrm{g} / \mathrm{day})$. Variables that changed estimates by more than $10 \%$ were kept in the final model. A sub-analysis was performed for each exposure, in which we excluded women who had been diagnosed with diabetes prior to the index pregnancy. Data were stratified by study year (1988-1997 and 1998-2012) due to interview differences and by FA intake to assess for potential effect measure modification. All analyses were performed using SAS 9.2 software [30].

\section{Results}

A total of 511 cases of SB and 868 controls (135 controls with minor malformations) were included for the years 1988 through 1997, while 265 cases of SB and 7,888 non-malformed controls were included for the years after 1998. Distributions of sociodemographic factors are presented in Table 1. For the years 1988 through 1997, of those mothers who were eligible and were asked to participate, mothers of $80 \%$ of cases and $68 \%$ of controls agreed to be interviewed [31]. For the years 1998 through 2012, the equivalent proportions were $71 \%$ of cases and $67 \%$ of controls [32].

\subsection{Smoking}

Due to missing smoking information, six cases and five controls were excluded from the 1988-1997 smoking analysis and three controls were excluded from the 1998-2012 smoking analysis. For all years, cigarette smoking was more common among younger mothers and those with fewer years of education (Table 2). In the earlier years, smoking was more prevalent in cases (32\%) compared to controls $(22 \%)$, while in the later years little difference was seen between cases (18\%) and controls $(15 \%)$. Among the factors examined as possible confounders, study center, maternal education, NSAID use, and folic acid antagonist medication use, were found to meet the criterion for confounding (i.e., addition of the variable caused more than a 10\% change in the estimate) for the years 1988 through 1997 only maternal race/ethnicity and education met the criterion for confounding in the later years.

For the years 1988 through 1997, no increased risk was observed for moderate smoking but there was a suggestion of an increased risk for heavier smokers (1-9 cigarettes/day: aOR: 1.2, 95\% CI: 0.8, 2.0; $\geq 10$ cigarettes/day: aOR: 1.3, 95\% CI: 0.9, 1.7) (Table 3). No increased risks were found in the later years (1-9 cigarettes/day: aOR: $1.1,95 \% \mathrm{CI}: 0.7,1.8$ and $\geq 10$ cigarettes/day: aOR: 1.0, 95\% CI: $0.7,1.6)$. When the data were stratified by folic acid intake, there was no appreciable change in risk among women with low FA intake (Figure 1). Furthermore, when women with pregestational diabetes were excluded from the smoking analysis there was no observable change in risks (1988-1993: 1-9 cigarettes/day: aOR: $1.3,95 \%$ CI: $0.8,2.0$; $\geq 10$ cigarettes/day: aOR: $1.3,95 \%$ CI: $0.9,1.7$; 1998-2012: 1-9 cigarettes/day: aOR: $1.1,95 \%$ CI: 0.7, 1.7; $\geq 10$ cigarettes/day: aOR: $1.0,95 \%$ CI: 0.6 , 1.6) (data not shown). 
Table 1. Maternal Demographics of Spina Bifida Cases and Controls, Birth Defects Study, 1988-2012.

\begin{tabular}{|c|c|c|c|c|c|c|c|c|}
\hline & \multicolumn{4}{|c|}{ 1988-1997 } & \multicolumn{4}{|c|}{ 1998-2012 } \\
\hline & \multicolumn{2}{|c|}{ Controls } & \multicolumn{2}{|c|}{ SB Cases } & \multicolumn{2}{|c|}{ Controls } & \multicolumn{2}{|c|}{ SB Cases } \\
\hline & $\mathbf{n}$ & $\%$ & $\mathbf{N}$ & $\%$ & $\mathbf{n}$ & $\%$ & $\mathbf{n}$ & $\%$ \\
\hline Total & 868 & & 511 & & 7,888 & & 265 & \\
\hline \multicolumn{9}{|l|}{ Maternal race/ethnicity } \\
\hline White, non-Hispanic & 782 & 90.1 & 455 & 89.0 & 5,645 & 71.6 & 166 & 62.6 \\
\hline Black, non-Hispanic & 46 & 5.3 & 30 & 5.9 & 662 & 8.4 & 28 & 10.6 \\
\hline Hispanic & 17 & 2.0 & 16 & 3.1 & 896 & 11.4 & 50 & 18.9 \\
\hline Other $\neq$ & 23 & 2.6 & 10 & 2.0 & 672 & 8.5 & 21 & 7.9 \\
\hline Missing & 0 & 0.0 & 0 & 0.0 & 13 & 0.2 & 0 & 0.0 \\
\hline \multicolumn{9}{|c|}{ Maternal age at conception } \\
\hline$<20$ years & 24 & 2.8 & 44 & 8.6 & 555 & 7.0 & 20 & 7.6 \\
\hline $20-24$ years & 91 & 10.5 & 102 & 20.0 & 1,149 & 14.6 & 43 & 16.2 \\
\hline $25-29$ years & 298 & 34.3 & 164 & 32.1 & 2,065 & 26.2 & 88 & 33.2 \\
\hline 30-34 years & 325 & 37.4 & 144 & 28.2 & 2,641 & 33.5 & 72 & 27.2 \\
\hline$\geq 35$ years & 130 & 15.0 & 57 & 11.2 & 1,457 & 18.5 & 42 & 15.9 \\
\hline Missing & 0 & 0.0 & 0 & 0.0 & 21 & 0.3 & 0 & 0.0 \\
\hline \multicolumn{9}{|l|}{ Maternal Education } \\
\hline$<12$ years & 55 & 6.3 & 83 & 16.2 & 720 & 9.1 & 40 & 15.1 \\
\hline 12 years & 187 & 21.5 & 181 & 35.4 & 1,452 & 18.4 & 64 & 24.2 \\
\hline$>12$ years & 625 & 72.0 & 247 & 48.3 & 5,708 & 72.4 & 160 & 60.4 \\
\hline Missing & 1 & 0.1 & 0 & 0.0 & 8 & 0.1 & 1 & 0.4 \\
\hline \multicolumn{9}{|c|}{ Study center (years in study) } \\
\hline Boston, MA (1976+) & 314 & 36.2 & 195 & 38.2 & 3,991 & 50.6 & 41 & 15.5 \\
\hline Philadelphia (1976+) & 186 & 21.4 & 155 & 30.3 & 1,567 & 19.9 & 91 & 34.3 \\
\hline Toronto (1979-2005) & 368 & 42.4 & 161 & 31.5 & 645 & 8.2 & 60 & 22.6 \\
\hline San Diego (2001+) & 0 & 0.0 & 0 & 0.0 & 1,131 & 14.3 & 38 & 14.3 \\
\hline New York $(2004+)$ & 0 & 0.0 & 0 & 0.0 & 554 & 7.0 & 35 & 13.2 \\
\hline \multicolumn{9}{|l|}{$B M I *(1993+)$} \\
\hline Underweight & 60 & 6.9 & 11 & 2.2 & 376 & 4.8 & 7 & 2.6 \\
\hline Normal & 449 & 51.7 & 78 & 15.3 & 4,814 & 61.0 & 128 & 48.3 \\
\hline Overweight & 152 & 17.5 & 34 & 6.7 & 1,549 & 19.6 & 55 & 20.8 \\
\hline Obese & 67 & 7.7 & 27 & 5.3 & 965 & 12.2 & 60 & 22.6 \\
\hline Missing & 140 & 16.1 & 361 & 70.6 & 184 & 2.3 & 15 & 5.7 \\
\hline \multicolumn{9}{|l|}{ Folic Acid } \\
\hline$<400 \mu \mathrm{g}$ & 561 & 64.6 & 386 & 75.5 & 3,499 & 44.4 & 123 & 46.4 \\
\hline$\geq 400 \mu \mathrm{g}$ & 297 & 34.2 & 112 & 21.9 & 4,222 & 53.5 & 131 & 49.4 \\
\hline Missing & 10 & 1.2 & 13 & 2.5 & 167 & 2.1 & 11 & 4.2 \\
\hline
\end{tabular}

₹ Other include mixed non-Hispanic, Native Hawaiian, Pacific Islander, Asian, Native American, or other

* BMI: Body Mass Index defined as $\frac{\mathrm{kg}}{\mathrm{m}^{2}}$ 
Table 2. Maternal Demographics According to Control Subject's Exposure During the First Month of Pregnancy, Birth Defects Study, $1988-2012$.

\begin{tabular}{|c|c|c|c|c|c|c|c|c|c|c|}
\hline & \multicolumn{2}{|c|}{$\begin{array}{l}\text { Smoking } \\
(1988-1997)\end{array}$} & \multicolumn{2}{|c|}{$\begin{array}{l}\text { Smoking } \\
(1998-2012)\end{array}$} & \multicolumn{2}{|c|}{$\begin{array}{c}\text { Alcohol Consumption } \\
(1988-1997)\end{array}$} & \multicolumn{2}{|c|}{$\begin{array}{c}\text { Alcohol Consumption } \\
(1998-2012)\end{array}$} & \multicolumn{2}{|c|}{$\begin{array}{l}\text { Coffee Consumption } \\
\quad(1998-2012)\end{array}$} \\
\hline & $\begin{array}{c}<1 \\
\mathrm{n}(\%)\end{array}$ & $\begin{array}{c}\geq 1 \\
\mathrm{n}(\%)\end{array}$ & $\begin{array}{c}<1 \\
\mathrm{n}(\%)\end{array}$ & $\begin{array}{c}\geq 1 \\
\mathrm{n}(\%)\end{array}$ & $\begin{array}{c}\text { No } \\
\text { n }(\%)\end{array}$ & $\begin{array}{c}\text { Yes } \\
\text { n }(\%)\end{array}$ & $\begin{array}{c}<1 \\
\mathrm{n}(\%)\end{array}$ & $\begin{array}{c}\geq 1 \\
\mathrm{n}(\%)\end{array}$ & $\begin{array}{c}<1 \\
\mathrm{n}(\%)\end{array}$ & $\begin{array}{c}\geq 1 \\
\mathrm{n}(\%)\end{array}$ \\
\hline \multicolumn{11}{|l|}{ Maternal race/ethnicity } \\
\hline White, non-Hispanic & $606(89.8)$ & $176(91.2)$ & $4,721(70.6)$ & $924(76.9)$ & $354(87)$ & $428(92.8)$ & $2,769(61.8)$ & $2,876(84.4)$ & $3,777(68.4)$ & $1,868(79)$ \\
\hline Black, non-Hispanic & $38(5.6)$ & $8(4.1)$ & $554(8.3)$ & $108(9)$ & $26(6.4)$ & $20(4.3)$ & 487 (10.9) & $175(5.1)$ & $579(10.5)$ & $170(7.2)$ \\
\hline Hispanic & $12(1.8)$ & $5(2.6)$ & $789(11.8)$ & $107(8.9)$ & $13(3.2)$ & $4(0.9)$ & $706(15.8)$ & $190(5.6)$ & $654(11.8)$ & $83(3.5)$ \\
\hline Otherf & $19(2.8)$ & $4(2.1)$ & $610(9.1)$ & $62(5.2)$ & $14(3.4)$ & $9(2)$ & $509(11.4)$ & $163(4.8)$ & $502(9.1)$ & $242(10.2)$ \\
\hline Missing & $0(0)$ & $0(0)$ & $12(0.2)$ & $1(0.1)$ & $0(0)$ & $0(0)$ & $9(0.2)$ & $4(0.1)$ & $11(0.2)$ & $2(0.1)$ \\
\hline \multicolumn{11}{|l|}{ Maternal Age } \\
\hline$<20$ years & $10(1.5)$ & $14(7.3)$ & $393(5.9)$ & $162(13.5)$ & $14(3.4)$ & $10(2.2)$ & $435(9.7)$ & $120(3.5)$ & $473(8.6)$ & $82(3.5)$ \\
\hline 20-24 years & $57(8.4)$ & $34(17.6)$ & $822(12.3)$ & $327(27.2)$ & $42(10.3)$ & $49(10.6)$ & $734(16.4)$ & $415(12.2)$ & $884(16)$ & $265(11.2)$ \\
\hline $25-29$ years & $228(33.8)$ & $70(36.3)$ & $1,751(26.2)$ & $314(26.1)$ & $152(37.3)$ & $146(31.7)$ & $1,202(26.8)$ & $863(25.3)$ & $1,473(26.7)$ & $592(25)$ \\
\hline 30-34 years & $270(40)$ & $55(28.5)$ & 2,391 (35.8) & $250(20.8)$ & $142(34.9)$ & $183(39.7)$ & $1,342(30)$ & $1,299(38.1)$ & $1,757(31.8)$ & $884(37.4)$ \\
\hline$\geq 35$ years & $110(16.3)$ & $20(10.4)$ & $1,308(19.6)$ & $149(12.4)$ & $57(14)$ & $73(15.8)$ & $753(16.8)$ & $704(20.7)$ & $918(16.6)$ & $539(22.8)$ \\
\hline Missing & $0(0)$ & $0(0)$ & $21(0.3)$ & $0(0)$ & $0(0)$ & $0(0)$ & $14(0.3)$ & $7(0.2)$ & $18(0.3)$ & $3(0.1)$ \\
\hline \multicolumn{11}{|l|}{ Maternal Education } \\
\hline$<12$ years & $29(4.3)$ & $26(13.5)$ & $498(7.4)$ & $222(18.5)$ & $31(7.6)$ & $24(5.2)$ & $584(13)$ & $136(4)$ & $564(10.2)$ & $156(6.6)$ \\
\hline 12 years & $118(17.5)$ & $69(35.8)$ & $1,010(15.1)$ & $442(36.8)$ & $103(25.3)$ & $84(18.2)$ & $971(21.7)$ & $481(14.1)$ & $1,002(18.1)$ & 450 (19) \\
\hline$>12$ years & $527(78.1)$ & $98(50.8)$ & $5,170(77.3)$ & $538(44.8)$ & $273(67.1)$ & $352(76.4)$ & $2,918(65.1)$ & $2,790(81.9)$ & $3,950(71.5)$ & $1,758(74.3)$ \\
\hline Missing & $1(0.1)$ & $0(0)$ & $8(0.1)$ & $0(0)$ & $0(0)$ & $1(0.2)$ & $7(0.2)$ & $1(0)$ & $7(0.1)$ & $1(0)$ \\
\hline \multicolumn{11}{|l|}{ Folic Acid } \\
\hline$<400$ & $419(62.1)$ & $142(73.6)$ & $2,705(40.5)$ & $794(66.1)$ & $251(61.7)$ & $310(67.2)$ & $2,055(45.9)$ & $1,444(42.4)$ & $2,459(44.5)$ & $1,040(44)$ \\
\hline $400+$ & $249(36.9)$ & $48(24.9)$ & $3,848(57.6)$ & $374(31.1)$ & $151(37.1)$ & $146(31.7)$ & $2,300(51.3)$ & $1,922(56.4)$ & $2,945(53.3)$ & $1,277(54)$ \\
\hline Missing & $7(1)$ & $3(1.6)$ & $133(2)$ & $34(2.8)$ & $5(1.2)$ & $5(1.1)$ & $125(2.8)$ & $42(1.2)$ & $119(2.2)$ & $48(2)$ \\
\hline \multicolumn{11}{|c|}{ Study center (years in study) } \\
\hline Boston, MA (1976+) & $243(36)$ & $71(36.8)$ & $3,324(49.7)$ & $667(55.5)$ & $133(32.7)$ & $181(39.3)$ & $2,182(48.7)$ & $1,809(53.1)$ & $2,619(47.4)$ & $1,372(58)$ \\
\hline Philadelphia (1976+) & $153(22.7)$ & $33(17.1)$ & $1,311(19.6)$ & $256(21.3)$ & $120(29.5)$ & $66(14.3)$ & $942(21)$ & $625(18.3)$ & $1,201(21.7)$ & $366(15.5)$ \\
\hline Toronto (1979-2005) & $279(41.3)$ & $89(46.1)$ & $536(8)$ & $109(9.1)$ & $154(37.8)$ & $214(46.4)$ & $334(7.5)$ & $311(9.1)$ & $435(7.9)$ & $210(8.9)$ \\
\hline San Diego (2001+) & $0(0)$ & $0(0)$ & $1,050(15.7)$ & $81(6.7)$ & $0(0)$ & $0(0)$ & $674(15)$ & $457(13.4)$ & $880(15.9)$ & $251(10.6)$ \\
\hline New York $(2004+)$ & $0(0)$ & $0(0)$ & $465(7)$ & $89(7.4)$ & $0(0)$ & $0(0)$ & $348(7.8)$ & $206(6)$ & $388(7)$ & $166(7)$ \\
\hline
\end{tabular}

₹ Other include mixed non-Hispanic, Native Hawaiian, Pacific Islander, Asian, Native American, or other 


\subsection{Alcohol}

Heavy drinking was examined by comparing mothers who drank $\geq 4$ drinks per drinking day any time during the first month to mothers who drank less or none (Table 3). Maternal education was the only factor that met the confounding criterion in the earlier years while NSAID use and folic acid antagonist medication use were identified for the later years. Slightly more mothers of cases reported heavy alcohol consumption than mothers of controls, but the difference was confounded by maternal education in the early years and NSAID and folic acid antagonist medication in later years, resulting in ORs that approximated the null. There was no change in the risk after stratification by folic acid intake for women who had low intake levels (Figure 1). When women with pregestational diabetes were excluded, there was no change in aORs (1988-1993: aOR: 1.1, 95\% CI: 0.7, 1.7; 1998-2012: aOR: $1.2,95 \%$ CI: $0.8,2.0$ ) (data not shown).

One case from the early period and seven controls from the later period were excluded from the alcohol analysis on frequency and intensity due to missing data on alcohol intake. Sociodemographic factors meeting the criterion for confounding were study center, maternal education, and FA intake. For frequency and intensity of alcohol intake, the reference groups were defined as mothers reporting $<1$ drinking day per week and < 1 drink per drinking day, respectively. When both frequency and intensity were considered together, women in both of these lower levels of intake constituted the reference group. Considered separately, neither frequency nor intensity measures was associated with increased SB risk, but women who were both frequent ( $\geq 3$ days/week) and intense ( $\geq 3$ drinks/day) drinkers were twice as prevalent among SB cases as controls (Table 4). However, the approximate 2-fold crude odds ( $\mathrm{cOR}=2.1$ ) of a frequent and intense drinking mother giving birth to an SB baby compared to the referent was confounded by FA intake, study center by year, and maternal education $(\mathrm{aOR}=1.2)$. Additionally, the exclusion of women with pregestational diabetes did not result in any observable changes in aORs (data not shown).

\subsection{Coffee}

Caffeine intake from coffee consumption was analyzed for data between 1998 through 2012; no subjects were excluded from the coffee analysis due to missing data. Only study center met the criterion for confounding. Compared to mothers who reported consuming no coffee, no increase in risk was observed for daily coffee drinkers ( $<1$ cup/day aOR: $0.7,95 \%$ CI: $0.4,1.1 ; 1$ cup/day aOR: 0.9 , 95\% CI: $0.6,1.3 ; \geq 2$ cups/day aOR: $0.6,95 \%$ CI: $0.3,1.2)$. Furthermore, there was no observed change in risk among mothers who had low intake levels of folic acid (Figure 1). When other sources of caffeine were included for the sensitivity analysis, no elevated risks were identified ( $<1 \mathrm{cup} /$ day aOR: 0.8, 95\% CI: 0.5, 1.4; 1 cup/day aOR: 0.9, 95\% CI: 0.4, 1.6; $\geq 2$ cups/day: aOR: $1.0,95 \%$ CI: 0.6, 1.7). Exclusion of women with pregestational diabetes did not result in any observable changes in aORs (<1 cup/day aOR: $0.7,95 \%$ CI: $0.5,1.4 ; 1$ cup/day aOR: $0.9,95 \%$ CI: $0.6,1.3$; $\geq 2$ cups/day: aOR: 0.6, 95\% CI: $0.3,1.2)$ (data not shown). 
Table 3. Association between Spina Bifida and Alcohol, Smoking, and Caffeine During the First Month of Pregnancy, Birth Defects Study, 1988-2012.

\begin{tabular}{|c|c|c|c|c|c|c|}
\hline & \multicolumn{2}{|c|}{ Cases } & \multicolumn{2}{|c|}{ Controls } & \multirow{2}{*}{$\operatorname{cOR}(95 \% \mathrm{CI})$} & \multirow{2}{*}{$\operatorname{aOR}(95 \% \mathrm{CI})$} \\
\hline & $\mathbf{n}$ & $\%$ & $\mathbf{n}$ & $\%$ & & \\
\hline \multicolumn{7}{|l|}{ Smoking } \\
\hline \multicolumn{7}{|l|}{$1988-1997^{1}$} \\
\hline None & 342 & 66.9 & 675 & 77.8 & Ref & Ref \\
\hline 1-9 cig/day & 38 & 7.4 & 53 & 6.1 & $1.4(0.9,2.2)$ & $1.2(0.8,2.0)$ \\
\hline $10+$ cigs/day & 125 & 24.5 & 135 & 15.6 & $1.8(1.4,2.4)$ & $1.3(0.9,1.7)$ \\
\hline Missing & 6 & 1.2 & 5 & 0.6 & - & - \\
\hline \multicolumn{7}{|l|}{$1998+{ }^{2}$} \\
\hline None & 218 & 82.3 & 6,686 & 84.8 & Ref & Ref \\
\hline 1-9 cig/day & 22 & 8.3 & 522 & 6.6 & $1.3(0.8,2.0)$ & $1.1(0.7,1.8)$ \\
\hline $10+\mathrm{cigs} / \mathrm{day}$ & 25 & 9.4 & 677 & 8.6 & $1.1(0.7,1.7)$ & $1.0(0.7,1.6)$ \\
\hline Missing & 0 & & 3 & $<0.1$ & - & - \\
\hline \multicolumn{7}{|l|}{ Alcohol } \\
\hline \multicolumn{7}{|l|}{$1988-1997^{3}$} \\
\hline No heavy drinking & 456 & 89.2 & 805 & 92.7 & Ref & Ref \\
\hline Heavy drinking ${ }^{\varphi}$ & 55 & 10.8 & 63 & 7.3 & $1.5(1.1,2.3)$ & $1.1(0.7,1.6)$ \\
\hline \multicolumn{7}{|l|}{$1998+{ }^{4}$} \\
\hline No heavy drinking & 239 & 90.6 & 7,385 & 93.6 & Ref & Ref \\
\hline Heavy drinking $^{\varphi}$ & 25 & 9.4 & 496 & 6.3 & $1.6(1.0,2.4)$ & $1.2(0.8,2.0)$ \\
\hline Missing & 1 & 0.4 & 7 & $<0.1$ & - & - \\
\hline \multicolumn{7}{|l|}{ Smoking and Alcohol use } \\
\hline \multicolumn{7}{|l|}{$1988-1997^{5}$} \\
\hline No smoking/ not heavy drinking & 322 & 69.0 & 646 & 79.8 & Ref & Ref \\
\hline $10+$ cigs per day/ heavy drinking & 29 & 6.2 & 24 & 3.0 & $2.4(1.4,4.2)$ & $1.3(0.7,2.3)$ \\
\hline Missing & 6 & 1.3 & 5 & 0.6 & - & - \\
\hline \multicolumn{7}{|l|}{$1998+{ }^{6}$} \\
\hline No smoking/ not heavy drinking & 214 & 88.1 & 6,433 & 87.4 & Ref & Ref \\
\hline $10+$ cigs per day/ heavy drinking & 11 & 4.5 & 149 & 2.0 & $2.2(1.2,4.2)$ & $2.0(1.0,3.8)$ \\
\hline Missing & 1 & 0.4 & 10 & 0.1 & - & - \\
\hline \multicolumn{7}{|l|}{ Caffeine from coffee } \\
\hline \multicolumn{7}{|l|}{$1998+{ }^{7}$} \\
\hline None & 205 & 77.4 & 5,523 & 70.0 & Ref & Ref \\
\hline$<1 \mathrm{cup} /$ day & 21 & 7.9 & 844 & 10.7 & $0.7(0.4,1.1)$ & $0.7(0.4,1.1)$ \\
\hline $1 \mathrm{cup} /$ day & 31 & 11.7 & 1084 & 13.7 & $0.8(0.5,1.1)$ & $0.9(0.6,1.3)$ \\
\hline $2+$ cups/day & 8 & 3.0 & 437 & 5.5 & $0.5(0.2,1.0)$ & $0.6(0.3,1.2)$ \\
\hline
\end{tabular}

${ }^{\varphi}$ Heavy drinking: Maternal report of drinking an average 4+ drinks per sitting at any time during the first lunar month;

${ }^{1}$ Adjusted for maternal education, study center, NSAID use, and folic acid antagonist medication use; ${ }^{2}$ Adjusted for maternal education and race/ethnicity; ${ }^{3}$ Adjusted for maternal education; ${ }^{4}$ Adjusted for NSAID use and folic acid antagonist medication use; ${ }^{5}$ Adjusted for maternal education, study center, NSAID use, and folic acid antagonist medication use; ${ }^{6}$ Adjusted for maternal education, race/ethnicity, NSAID use, and folic acid antagonist medication use; ${ }^{7}$ Adjusted for study center. 
Figure 1. Adjusted Odds Ratios for Associations between Spina Bifida and Exposure for All Subjects and Subjects with $<400 \mu \mathrm{g}$ Daily Folic Acid intake, Birth Defects Study 1988-2012.

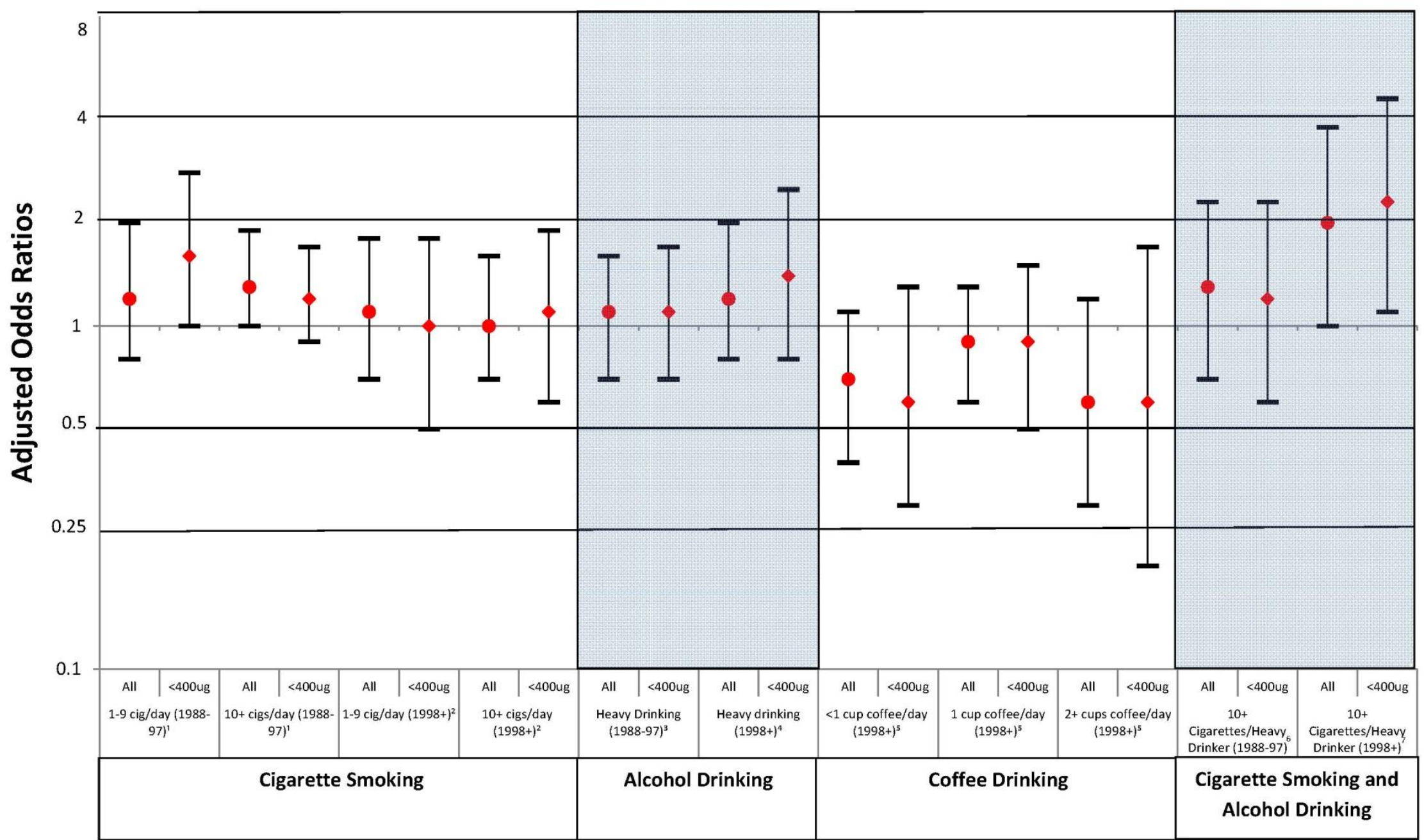

${ }^{1}$ Adjusted for maternal education, study center, NSAID use, and folic acid antagonist medication use; ${ }^{2}$ Adjusted for maternal education and race/ethnicity; ${ }^{3}$ Adjusted for maternal education; ${ }^{4}$ Adjusted for NSAID use and folic acid antagonist medication use; ${ }^{5}$ Adjusted for study center; ${ }^{6}$ Adjusted for maternal education, study center, NSAID use, and folic acid antagonist medication use; ${ }^{7}$ Adjusted for NSAID use and folic acid antagonist medication use. 
Table 4. Association between Spina Bifida and Alcohol Consumption by Frequency and Intensity During the First Month of Pregnancy, Birth Defects Study, 1988-2012.

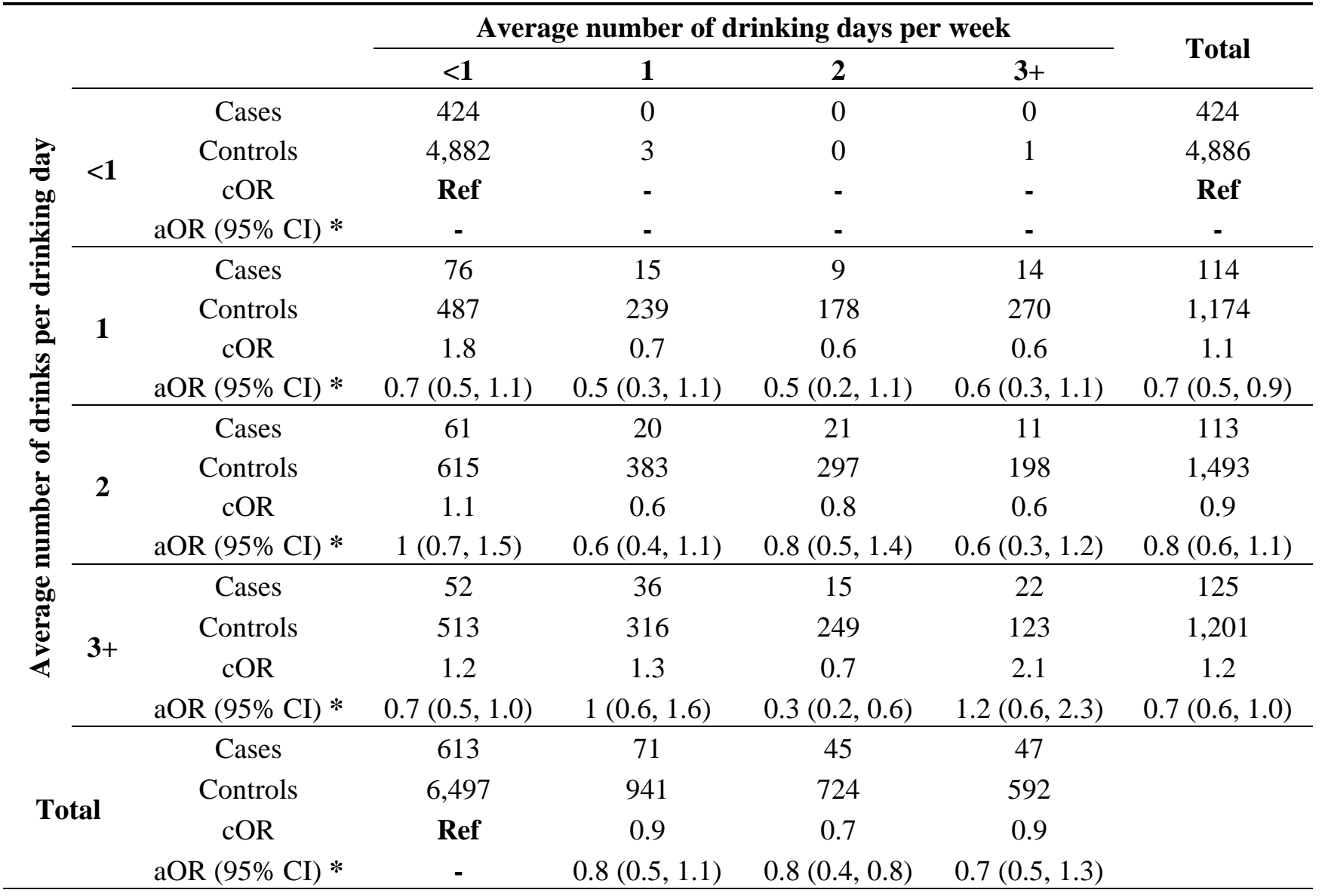

* Adjusted for folic acid intake, study center by year, and maternal education.

\subsection{Smoking, Alcohol, and Coffee Interaction}

Because there was only one case in both the highest exposure group of caffeine and smoking, and none in the highest caffeine and heavy drinking, we did not assess these interactions in relation to SB risk. Women who reported both smoking 10+ cigarettes per day and heavy alcohol drinking were compared to women who did not smoke and were not heavy drinkers. Confounders identified in the early years were study center, maternal education, NSAID use, and folate antagonist medication use. In the later years confounders that met the criterion were maternal education, race/ethnicity, NSAID use, and folate antagonist medication use. Prior to 1998, there was no observed association for SB risk and the combination of 10+ cigarettes and heavy drinking (aOR: $1.395 \% \mathrm{CI}: 0.7,2.3$ ). However, in the later years, a modest association was observed but the confidence interval included the null (aOR: $2.095 \%$ CI: 1.0, 3.8). After stratifying women according to folic acid intake, there was little change in risk among mothers in both periods; however the elevated risk among mothers in the later years was more apparent (aOR: 2.3 95\% CI: 1.1, 4.6) (Figure 1). 


\section{Discussion}

In this case-control study the risk for SB does not appear to be associated with cigarette smoking, alcohol consumption, and coffee consumption at the levels of intake observed in the study. These null results, with narrow CIs, are consistent with many previous reports [12-14,17,33-42] but are in contrast to a smaller number of studies with positive associations $[11,12,38,43]$.

\subsection{Smoking}

Our results for the earlier years of the study showed a small increase in risk for SB at each level of cigarette smoking, with a slight dose effect. In the later years, however, both levels of smoking exposure resulted in a null association with SB risk. The discontinuity between findings in the two time periods could be due to several factors. First, beginning in 1998, interviews were conducted over the phone as opposed to in-person. If in-person interviews elicit more accurate responses, then our findings from the more recent years would be more vulnerable to bias. A second possible explanation is the use of different controls prior to and following 1993; controls with minor malformations and certain medical conditions were used prior to 1993. However, a post hoc analysis of data collected before and after that change in the composition of control subjects revealed similar results (data not shown). Another possibility is uncontrolled confounding by factors that vary in distribution between the two time periods. For example, if FA is a true confounder and we tended to underestimate intakes, a larger proportion of women in the early years would be affected by such misclassification when intakes in general were lower, as observed in other population-based studies of intakes and blood folate levels [9]. Thus, uncontrolled confounding by FA intake would be greater in the earlier years. Finally, the percentage of heavier smokers has decreased over the past two decades in our study and in the general population of pregnant women [44-46]. If cigarette smoking has a threshold effect on SB risk, our null findings in the later years might be due the lower levels of smoking within the highest exposure category. The finding of no association has been observed in other studies $[14,42,43]$. One study broadly categorized smoking exposure as $\leq 5$ and $>5$ cigarettes per day, while two others used finer categories of exposure (1-19, $\geq 20$ and 1-14, 15-24, $\geq 25$ cigarettes/day).

\subsection{Alcohol}

In the present study, neither frequent nor intense alcohol consumption was associated with SB risk, which is consistent with previous studies $[11,17,34]$. While the frequency of mothers who drank at least three drinks per drinking occasion and three or more days per week was more common among SB cases, this pattern was due to confounding by FA intake, study center and period, and education. With regard to the impact of heavy drinking during the first 28 days after LMP, we found no association with the risk of SB. Results of previous studies using similar categories of exposure have been inconclusive. One study observed an increase in the risk of NTDs (OR: 1.7, 95\% CI: 0.8, 3.6) [11] while two studies of SB reported null results [14,17]. 


\subsection{Coffee}

We found that maternal exposure to caffeine from coffee was not associated with an increased risk of SB. Rather, ORs for varying levels of intake were all below 1.0, but the $95 \%$ confidence intervals included 1.0. Furthermore, we observed very little confounding of our risk estimates for caffeine. Consistent with our findings, two previous studies found no association between NTDs and coffee or caffeine [13,35] and one found a suggestion of a protective effect [36]. In one previous study, there was a slight increase in the risk for SB among mothers who consumed coffee [12]. However, similar to our finding, there was no dose effect observed, which the authors cited as evidence against a causal association [12].

\subsection{Smoking, Alcohol, and Coffee Interaction}

The combination of smoking 10+ cigarettes per day and heavy drinking was not associated with SB risk in the earlier years of the study, but a doubling in risk in the later years. As described above in our discussion of cigarette smoking results, the discontinuity in our findings between the two time periods could be due to different interviewing formats or uncontrolled confounding. Previous studies of smoking and alcohol exposures in relation to NTDs did not examine the interaction of these two variables [14,17,42,43], but one study did show an increase (aOR: 12.7 95\% CI: $3.5,45.3$ ) for the risk of congenital cardiac defects and the interaction of maternal binge drinking ( $\geq 5$ drinks on at least one occasion) and smoking (yes, no) in the three months prior to pregnancy [47].

\subsection{Bias/Limitations}

There were limitations to our study. First, reported exposures suggest that only a small percentage of women are in the highest exposure group, which limits our ability to study the effects of these exposures and decreases the precision of our estimates. The problem was exacerbated when the data were stratified by FA intake. Additionally, data on exposure were collected by maternal self-report which likely has high sensitivity but low specificity in that some women may under-report. Such misclassification may be greater for exposures with the most stigma [48] in pregnancy (e.g., cigarettes and alcohol). If mothers of cases are more likely to deny high level use, effect estimates would be biased downward. Studies have shown that reliability of self-reported smoking during pregnancy is generally good [49-51], but subjects may underreport the amount they smoke [52,53]. Alcohol intake in pregnancy was found to be under-reported by $44 \%$ in one study [48]. In a study examining coffee intake reporting, it was found that amounts reported by FFQ correlated well with amounts reported by daily food diaries; however, absolute intake differed between the FFQ and the daily food diary [54]. Accuracy of reporting exposure to cigarettes, alcohol, and coffee is further complicated by our early pregnancy exposure window, which is a time when women often change their exposure patterns. Further, exposures in the earliest days of lunar month two may be etiologically relevant but were not considered in our exposure algorithms. Therefore, we cannot rule out the possibility of misclassification of our exposures.

Power was maximized and bias minimized through systematic approaches in the study design. This study included a large number of cases and controls to maximize the number of subjects within each 
stratum of exposure. During maternal interviews, information was gathered on frequency, quantity, and timing through the use of a standardized questionnaire and detailed support material (e.g., calendars) to help participants give complete and accurate responses. To minimize any potential bias stemming from maternal recall, reporting accuracy was maximized for both cases and controls through highly structured interviews conducted within six months of birth or termination by skilled and experienced nurse interviewers who were unaware of the study hypotheses.

\section{Conclusions}

We have investigated the association between the risk of SB and periconceptional cigarette, alcohol, and coffee consumption, using a large geographically diverse case-control study. Our findings suggest that there is no increased risk for SB among women who consumed cigarettes, alcohol, and caffeine. This observation held true among women who did not consume the recommended amount of folic acid. Despite the fact that our findings are similar to those of previous studies, the results should still be interpreted cautiously due to limitations, including low precision for the highest levels of intake.

\section{Acknowledgments}

This work is funded by the Centers for Disease Control and Prevention (DD000697). The findings and conclusions in this report are those of the authors and do not necessarily represent the official position of the Centers for Disease Control and Prevention. We thank Dawn Jacobs, Fiona Rice, Rita Krolak, Kathleen Sheehan, Moira Quinn, Clare Coughlin, Laurie Cincotta, Mary Thibeault, Nancy Rodriquez-Sheridan, Ileana Gatica, Laine Catlin Fletcher, Carolina Meyers, Joan Shander, Julia Venanzi, Mark Abcede, and Judy Jean for their assistance in data collection, and Nastia Dynkin for computer programming; the staff of the Massachusetts Department of Public Health Center for Birth Defects Research and Prevention and the Massachusetts Registry of Vital Records, Charlotte Druschel and the New York State Health Department, and Christina Chambers and Kenneth Jones of the University of California, San Diego, as well as the medical and nursing staff at all participating hospitals for assistance with case ascertainment: Baystate Medical Center, Beth Israel Deaconess Medical Center, Boston Medical Center, Brigham \& Women's Hospital, Brockton Hospital, Cambridge Hospital Caritas Good Samaritan Medical Center, Charlton Memorial Hospital, Children's Hospital, Holy Family Hospital, Kent Hospital, Lawrence General Hospital, Lowell General Hospital, Melrose-Wakefield Hospital, Metro West Medical Center-Framingham, Mt. Auburn Hospital, New England Medical Center, Newton-Wellesley Hospital, North Shore Medical Center, Rhode Island Hospital, Saints Memorial Medical Center, South Shore Hospital, Southern New Hampshire Medical Center, St. Elizabeth's Medical Center, St. Luke's Hospital, UMASS Memorial Health Care, Women \& Infants' Hospital, Abington Memorial Hospital, Albert Einstein Medical Center, Alfred I. duPont Hospital for Children, Bryn Mawr Hospital, Chester County Hospital, Children's Hospital of Philadelphia, Christiana Care Health Services, Community Hospital, Crozer-Chester Medical Center, Doylestown Hospital, Frankford Hospital, Hahnemann University Hospital, The Hospital of the University of Pennsylvania, Lankenau Hospital, Lancaster General Hospital, Lehigh Valley Hospital, Nanticoke Memorial Hospital, Pennsylvania Hospital, Sacred Heart Hospital, St. Christopher's Hospital for Children, St. Mary Medical Center, Temple University Health Sciences Center, Reading 
Hospital \& Medical Center, Thomas Jefferson University Hospital, Grand River Hospital, Guelph General Hospital, Hamilton Health Sciences Corporation, The Hospital for Sick Children, Humber River Regional Hospital-Church Site, Humber River Regional Hospital-Finch Site, Joseph Brant Memorial Hospital, Lakeridge Health Corporation, London Health Sciences Center, Mt. Sinai Hospital, North York General Hospital, Oakville Trafalgar Memorial Hospital, Scarborough HospitalGeneral Division, Scarborough Hospital-Grace Division, St. Joseph's Health Centre-London, St. Joseph's Health Centre-Toronto, St. Joseph's Healthcare-Hamilton, St. Michael's Hospital, Sunnybrook \& Women's College Health Sciences Center, Toronto East General Hospital, Toronto General Hospital, Trillium Health Center, William Osler Heath Centre, York Central Hospital, York County Hospital, Alvarado Hospital, Balboa Naval Medical Center, Camp Pendleton Naval Hospital, Children's Hospital and Health Center, Kaiser Zion Medical Center, Palomar Medical Center, Pomerado Hospital, Scripps Mercy Hospital, Scripps Memorial Hospital-Chula Vista, Scripps Memorial Hospital-Encinitas, Scripps Memorial Hospital-La Jolla, Sharp Chula Vista Hospital, Sharp Coronado Hospital, Sharp Grossmont Hospital, Sharp Mary Birch Hospital, Tri-City Medical Center, and UCSD Medical Center; we particularly thank all the mothers who participated in the study.

\section{Conflict of Interest}

Martha Werler owns less than \$5,000 in Starbucks Corporation stock. Investigators have no other conflicts to report.

\section{References}

1. Parker, S.E.; Mai, C.T.; Canfield, M.A.; Rickard, R.; Wang, Y.; Meyer, R.E.; Anderson, P.; Mason, C.A.; Collins, J.S.; Kirby, R.S.; et al. Updated national birth prevalence estimates for selected birth defects in the United States, 2004-2006. Birth Defects Res. A: Clin. Mol. Teratol. 2010, 88, 1008-1016.

2. Botto, L.D.; Moore, C.A.; Khoury, M.J.; Erickson, J.D. Neural-tube defects. N. Engl. J. Med. 1999, 341, 1509-1519.

3. Berry, R.J.; Li, Z.; Erickson, J.D.; Li, S.; Moore, C.A.; Wang, H.; Mulinare, J.; Zhao, P.; Wong, L.-Y.C.; Gindler, J.; et al. Prevention of neural-tube defects with folic acid in China. N. Engl. J. Med. 1999, 341, 1485-1490.

4. Czeizel, A.E.; Dudas, I. Prevention of the first occurrence of neural-tube defects by periconceptional vitamin supplementation. N. Engl. J. Med. 1992, 327, 1832-1835.

5. Werler, M.M.; Shapiro, S.; Mitchell, A.A. Periconceptional folic acid exposure and risk of occurrent neural tube defects. JAMA 1993, 269, 1257-1261.

6. MRC Vitamin Study Research Group. Prevention of neural tube defects: Results of the Medical Research Council Vitamin Study. Lancet 1991, 338, 131-137. Available online: http://www.thelancet.com/journals/lancet/article/PII0140-6736\%2891\%2990133-A/abstract (accessed on 30 July 2013). 
7. Tinker, S.C.; Cogswell, M.E.; Devine, O.; Berry, R.J. Folic acid intake among US women aged 15-44 years, National Health and Nutrition Examination Survey, 2003-2006. Am. J. Prev. Med. 2010, 38, 534-542.

8. Dietrich, M.; Brown, C.J.; Block, G. The effect of folate fortification of cereal-grain products on blood folate status, dietary folate intake, and dietary folate sources among adult non-supplement users in the United States. J. Am. Coll. Nutr. 2005, 24, 266-274.

9. Jacques, P.F.; Selhub, J.; Bostom, A.G.; Wilson, P.W.; Rosenberg, I.H. The effect of folic acid fortification on plasma folate and total homocysteine concentrations. N. Engl. J. Med. 1999, 340, 1449-1454.

10. Wasserman, C.R.; Shaw, G.M.; O’Malley, C.D.; Tolarova, M.M.; Lammer, E.J. Parental cigarette smoking and risk for congenital anomalies of the heart, neural tube, or limb. Teratology 1998, 53, 261-267.

11. Suarez, L.; Felkner, M.; Brender, J.D.; Canfield, M.; Hendricks, K. Maternal exposures to cigarette smoke, alcohol, and street drugs and neural tube defect occurrence in offspring. Matern. Child Health J. 2008, 12, 394-401.

12. Schmidt, R.J.; Romitti, P.A.; Burns, T.L.; Browne, M.L.; Druschel, C.M.; Olney, R.S. Maternal caffeine consumption and risk of neural tube defects. Birth Defects Res. A: Clin. Mol. Teratol. 2009, 85, 879-889.

13. McDonald, A.D.; Armstrong, B.G.; Sloan, M. Cigarette, alcohol, and coffee consumption and congenital defects. Am. J. Public Health 1992, 82, 91-93.

14. Grewal, J.; Carmichael, S.L.; Ma, C.; Lammer, E.J.; Shaw, G.M. Maternal periconceptional smoking and alcohol consumption and risk for select congenital anomalies. Birth Defects Res. A: Clin. Mol. Teratol. 2008, 82, 519-526.

15. Källén, K. Maternal smoking, body mass index, and neural tube defects. Am. J. Epidemiol. 1998, 147, 1103-1111.

16. Friedman, J.M. Can maternal alcohol ingestion cause neural tube defects? J. Pediatr. 1982, 101, 232-234.

17. Makelarski, J.A.; Romitti, P.A.; Sun, L.; Burns, T.L.; Druschel, C.M.; Suarez, L.; Olshan, A.F.; Siega-Riz, A.M.; Olney, R.S.; National Birth Defects Prevention Study. Periconceptional maternal alcohol consumption and neural tube defects. Birth Defects Res. A: Clin. Mol. Teratol. 2013, 97, 152-160.

18. Momoi, N.; Tinney, J.P.; Liu, L.J.; Elshershari, H.; Hoffmann, P.J.; Ralphe, J.C.; Keller, B.B.; Tobita, K. Modest maternal caffeine exposure affects developing embryonic cardiovascular function and growth. Am. J. Physiol. Heart Circ. Physiol. 2008, 294, H2248-H2256.

19. Lewis, D.P.; van Dyke, D.C.; Stumbo, P.J.; Berg, M.J. Drug and environmental factors associated with adverse pregnancy outcomes. Part I: Antiepileptic drugs, contraceptives, smoking, and folate. Ann. pharmacother. 1998, 32, 802-817.

20. Piyathilake, C.J.; Macaluso, M.; Hine, R.J.; Richards, E.W.; Krumdieck, C.L. Local and systemic effects of cigarette smoking on folate and vitamin B-12. Am. J. Clin. Nutr. 1994, 60, 559-566. 
21. Hillman, R.; Steinberg, S. The effects of alcohol on folate metabolism. Annu. Rev. Med. 1982, 33, 345-354.

22. Russell, R.M.; Rosenberg, I.H.; Wilson, P.D.; Iber, F.L.; Oaks, E.B.; Giovetti, A.C.; Otradovec, C.; Karwoski, P.; Press, A. Increased urinary excretion and prolonged turnover time of folic acid during ethanol ingestion. Am. J. Clin. Nutr. 1983, 38, 64-70.

23. Ulvik, A.; Vollset, S.E.; Hoff, G.; Ueland, P.M. Coffee consumption and circulating B-vitamins in healthy middle-aged men and women. Clin. Chem. 2008, 54, 1489-1496.

24. Ahrens, K.; Yazdy, M.M.; Mitchell, A.A.; Werler, M.M. Folic acid intake and spina bifida in the era of dietary folic acid fortification. Epidemiology 2011, 22, 731-737.

25. Louik, C.; Lin, A.E.; Werler, M.M.; Hernández-Díaz, S.; Mitchell, A.A. First-trimester use of selective serotonin-reuptake inhibitors and the risk of birth defects. N. Engl. J. Med. 2007, 356, 2675-2683.

26. Mitchell, A.A.; Rosenberg, L.; Shapiro, S.; Slone, D. Birth defects related to Bendectin use in pregnancy. JAMA 1981, 245, 2311-2314.

27. Werler, M.M.; Hayes, C.; Louik, C.; Shapiro, S.; Mitchell, A.A. Multivitamin supplementation and risk of birth defects. Am. J. Epidemiol. 1999, 150, 675-682.

28. Institute of Medicine. Dietary Reference Intakes for Thiamin, Riboflavin, Niacin, Vitamin B6, Folate, Vitamin B12, Pantothenic Acid, Biotin, and Choline; National Academies Press: Washington, DC, USA, 1998.

29. Willett, W.; Stampfer, M.J. Total energy intake: Implications for epidemiologic analyses. Am. J. Epidemiol. 1986, 124, 17-27.

30. Release Version 9.2. Cary, NC., SAS Institute Inc. 2002-2008. Available online: http://www.sas.com/ presscenter/guidelines.html (accessed on 30 July 2013).

31. Yazdy, M.M.; Liu, S.; Mitchell, A.A.; Werler, M.M. Maternal dietary glycemic intake and the risk of neural tube defects. Am. J. Epidemiol. 2010, 171, 407-414.

32. Yau, W.P.; Mitchell, A.A.; Lin, K.J.; Werler, M.M.; Hernandez-Diaz, S. Use of decongestants during pregnancy and the risk of birth defects. Am. J. Epidemiol. 2013, 178, 198-208.

33. Martínez-Frías, M.L.; Bermejo, E.; Rodríguez-Pinilla, E.; Frías, J.L. Risk for congenital anomalies associated with different sporadic and daily doses of alcohol consumption during pregnancy: A case-control study. Birth Defects Res. A: Clin. Mol. Teratol. 2004, 70, 194-200.

34. Shaw, G.M.; Nelson, V.; Carmichael, S.L.; Lammer, E.J.; Finnell, R.H.; Rosenquist, T.H. Maternal periconceptional vitamins: Interactions with selected factors and congenital anomalies? Epidemiology 2002, 13, 625-630.

35. Kurppa, K.; Holmberg, P.C.; Kuosma, E.; Saxén, L. Coffee consumption during pregnancy and selected congenital malformations: A nationwide case-control study. Am. J. Public Health 1983, 73, 1397-1399.

36. Rosenberg, L.; Mitchell, A.A.; Shapiro, S.; Slone, D. Selected birth defects in relation to caffeine-containing beverages. JAMA 1982, 247, 1429-1432. 
37. Seidman, D.S.; Ever-Hadani, P.; Gale, R. Effect of maternal smoking and age on congenital anomalies. Obstet. Gynecol. 1990, 76, 1046-1050.

38. Evans, D.R.; Newcombe, R.G.; Campbell, H. Maternal smoking habits and congenital malformations: A population study. Br. Med. J. 1979, 2, 171-173.

39. Malloy, M.H.; Kleinman, J.C.; Bakewell, J.M.; Schramm, W.F.; Land, G.H. Maternal smoking during pregnancy: No association with congenital malformations in Missouri 1980-83. Am. J. Public Health 1989, 79, 1243-1246.

40. Shiono, P.H.; Klebanoff, M.A.; Berendes, H.W. Congenital malformations and maternal smoking during pregnancy. Teratology 1986, 34, 65-71.

41. Kelsey, J.L.; Dwyer, T.; Holford, T.R.; Bracken, M.B. Maternal smoking and congenital malformations: An epidemiological study. J. Epidemiol. Community Health 1978, 32, 102-107.

42. Shaw, G.M.; Velie, E.M.; Morland, K.B. Parental recreational drug use and risk for neural tube defects. Am. J. Epidemiol. 1996, 144, 1155-1160.

43. Suarez, L.; Ramadhani, T.; Felkner, M.; Canfield, M.A.; Brender, J.D.; Romitti, P.A.; Sun, L. Maternal smoking, passive tobacco smoke, and neural tube defects. Birth Defects Res. A: Clin. Mol. Teratol. 2011, 91, 29-33.

44. Colman, G.J.; Joyce, T. Trends in smoking before, during, and after pregnancy in ten states. Am. J. Prev. Med. 2003, 24, 29-35.

45. Mathews, T.J. Smoking During Pregnancy in the 1990s. In National Vital Statistics Reports; National Center for Health Statistics: Hyattsville, MD, USA, 2001; Volume 49.

46. Ebrahim, S.H.; Floyd, R.L.; Merritt, R.K., II; PDecoufle, P. Trends in pregnancy-related smoking rates in the united states, 1987-1996. JAMA 2000, 283, 361-366.

47. Mateja, W.A.; Nelson, D.B.; Kroelinger, C.D.; Ruzek, S.; Segal, J. The association between maternal alcohol use and smoking in early pregnancy and congenital cardiac defects. J. Womens Health 2012, 21, 26-34

48. Jacobson, S.W.; Jacobson, J.L.; Sokol, R.J.; Martier, S.S.; Ager, J.W.; Kaplan, M.G. Maternal recall of alcohol, cocaine, and marijuana use during pregnancy. Neurotoxicol. Teratol. 1991, 13, 535-540.

49. Paganini-Hill, A.; Ross, R.K. Reliability of recall of drug usage and other health-related information. Am. J. Epidemiol. 1982, 116, 114-122.

50. Tomeo, C.A.; Rich-Edwards, J.W.; Michels, K.B.; Berkey, C.S.; Hunter, D.J.; Frazier, A.L.; Willett, W.C.; Buka, S.L. Reproducibility and validity of maternal recall of pregnancy-related events. Epidemiology 1999, 10, 774-776.

51. Yawn, B.P.; Suman, V.J.; Jacobsen, S.J. Maternal recall of distant pregnancy events. J. Clin. Epidemiol. 1998, 51, 399-405.

52. George, L.; Granath, F.; Johansson, A.L.; Cnattingius, S. Self-reported nicotine exposure and plasma levels of cotinine in early and late pregnancy. Acta obstetricia et gynecologica Scandinavica 2006, 85, 1331-1337. 
53. Ford, R.; Tappin, D.; Schluter, P.; Wild, C. Smoking during pregnancy: How reliable are maternal self reports in New Zealand? J. Epidemiol. Community Health 1997, 51, 246-251.

54. Schliep, K.C.; Schisterman, E.F.; Mumford, S.L.; Perkins, N.J.; Ye, A.; Pollack, A.Z.; Zhang, C.; Porucznik, C.A.; VanDerslice, J.A.; Stanford, J.B. Validation of different instruments for caffeine measurement among premenopausal women in the BioCycle study. Am. J. Epidemiol. 2013, 177, 690-699.

(C) 2013 by the authors; licensee MDPI, Basel, Switzerland. This article is an open access article distributed under the terms and conditions of the Creative Commons Attribution license (http://creativecommons.org/licenses/by/3.0/). 